\title{
RESÍDUOS SÓLIDOS URBANOS: PERCEPÇÃO AMBIENTAL NA MICROBACIA DO CÓRREGO DO TIJUCO PRETO NO MUNICÍPIO DE SÃO CARLOS (SP)
}

\author{
Aline Doria de Santi ${ }^{1}$ \\ Giulia Guillen Mazzuco² \\ Taynara Letícia Barbosa ${ }^{3}$ \\ Barbara Hass Miguel ${ }^{4}$ \\ Natália Lopes Zamaroli ${ }^{5}$ \\ Haydée Torres de Oliveira ${ }^{6}$
}

Resumo: O presente trabalho teve como objetivo sensibilizar os participantes do Programa Escola da Família na Instituição de Ensino Antônio Militão de Lima, localizado no município de São Carlos - SP, sobre a problemática do descarte inadequado de resíduos sólidos na microbacia hidrográfica em que a instituição está inserida. As atividades desenvolvidas com os participantes envolveram uma trilha às margens do córrego do Tijuco Preto, a elaboração do "Muro dos Problemas" e do "Rio dos Desejos" e um debate sobre os problemas identificados e as possíveis ações para minimizá-los. Os resultados desta experiência demonstraram a potencialidade de projetos de Educação Ambiental na sensibilização e formação da consciência dos cidadãos em relação à temática ambiental.

Palavras-chave: Educação Ambiental; Resíduos Sólidos; Tijuco Preto.

${ }^{1}$ Universidade Federal de São Carlos. E-mail: linesanti88@yahoo.com.br

2 Universidade Federal de São Carlos. E-mail: guillen.giulia@gmail.com

3 Universidade Federal de São Carlos. E-mail: taynaraleticiabs@gmail.com

${ }^{4}$ Universidade Federal de São Carlos. E-mail: babs.hass@gmail.com

5 Universidade Federal de São Carlos. E-mail: nazamaroli@gmail.com

6 Universidade Federal de São Carlos. E-mail: haydee.ufscar@gmail.com

Revbea, São Paulo, V. 11, № 4: 29-41, 2016.

revista brasileira educação ambiental 


\section{Introdução}

A crise ambiental decorrente da relação desarmônica entre o ser humano e a natureza reflete em um grande desafio político, epistemológico e ético aos que tentam reverter essa problemática. A Carta da Terra busca a conciliação destes aspectos a fim de promover o desenvolvimento sustentável e uma sociedade mais justa e pacífica, em âmbito global, por intermédio do diálogo intercultural, em torno de objetivos comuns e valores compartilhados. A educação tem um papel fundamental neste conceito, sendo um caminho para obter resultados positivos e condizentes com os quatro princípios descritos por ela: respeitar e cuidar da comunidade da vida; integridade ecológica; justiça social e econômica; democracia; não violência e paz (CARTA DA TERRA, 2000). Neste sentido, a comunicação através do ensino deve ser objeto de uma visão crítica, que analise historicamente as relações e atividades humanas e os seus impactos negativos ao meio ambiente (CARVALHO, 1999, p.11).

A sociedade tem um papel fundamental tanto na degradação dos recursos naturais, quanto na preservação do meio ambiente. Isto posto, a prática de educação ambiental (EA) deve conduzir a população a ter um posicionamento crítico sobre a atual situação, permitindo que ela transforme seus hábitos e costumes sociais de forma a promover o desenvolvimento sustentável. A dimensão da EA representa a possibilidade de lidar com conexões entre diferentes dimensões humanas, possibilitando entrelaçamentos e trânsitos entre múltiplos saberes, sendo objeto para fortalecer a cidadania ambiental convergente e multirreferencial (JACOBI, 2005).

Segundo Sauvé (2005), a educação ambiental não compreende simplesmente uma forma ou ferramenta para resolução dos problemas ambientais. Sua atuação induz dinâmicas sociais, primeiramente na comunidade local, e posteriormente em maior dimensão, promovendo uma visão colaborativa e crítica das realidades existentes entre o ser humano e o meio ambiente, possibilitando uma concepção individual e criativa dos problemas locais e de possível soluções para os mesmos.

A escolha da abordagem a ser utilizada nas práticas de EA deve ser coerente com os objetivos do projeto e contextualizada com a realidade social vigente. Os princípios impressos na Carta da Terra e a abordagem crítica utilizada em práticas educacionais unem aspectos sociais e ambientais, considerando também a diversidade cultural, o conhecimento científico e as questões políticas.

Frente a estes aspectos o projeto desenvolvido teve como perspectiva o comprometimento com a transformação da realidade, focando nas relações entre os indivíduos participantes, buscando não apenas uma transmissão unilateral de conhecimentos, mas sim uma efetiva troca de experiências.

Santi e Mazzuco (2014) apresentaram em seu estudo a problemática que envolve o descarte inadequado de resíduos sólidos na área em que se desenvolveu 0 projeto em questão. A grande quantidade de resíduos domiciliares, de construção civil e perigosos, descartados de forma inadequada 
às margens do córrego do Tijuco Preto, geram riscos potenciais de poluição do solo, das matas ciliares e dos recursos hídricos (Figura 1), caracterizando-se em um problema ambiental e de saúde pública. Para mitigar esta problemática, faz-se necessária a implantação de programas de educação ambiental que sensibilizem a população sobre as consequências negativas do descarte inadequado, além de apontar as formas adequadas de descarte, contribuindo com a disseminação da importância do gerenciamento adequado de resíduos.

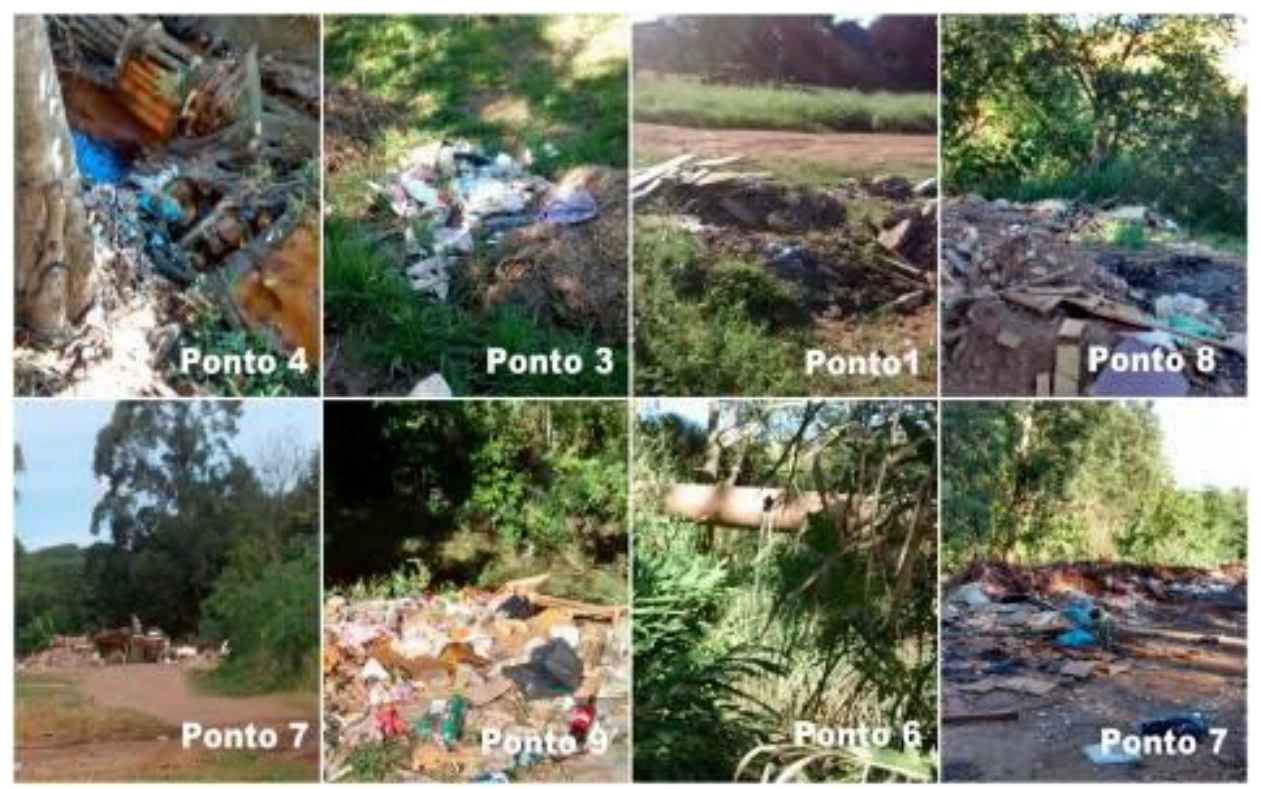

Figura 1: Resíduos dispostos de forma inadequada na microbacia do Tjuco Preto.

Fonte: SANTI; MAZZUCO (2014)

Frente a este cenário, identificou-se a Escola Estadual Professor Antônio Militão de Lima, localizada na microbacia do Tijuco Preto (Figura 2) no município de São Carlos - SP, como um local estratégico para a sensibilização e a construção de conhecimento junto à população, buscando outros olhares sobre o local, para assim semear o pensar coletivo sobre os problemas da área e as possíveis saídas para controlá-los. 


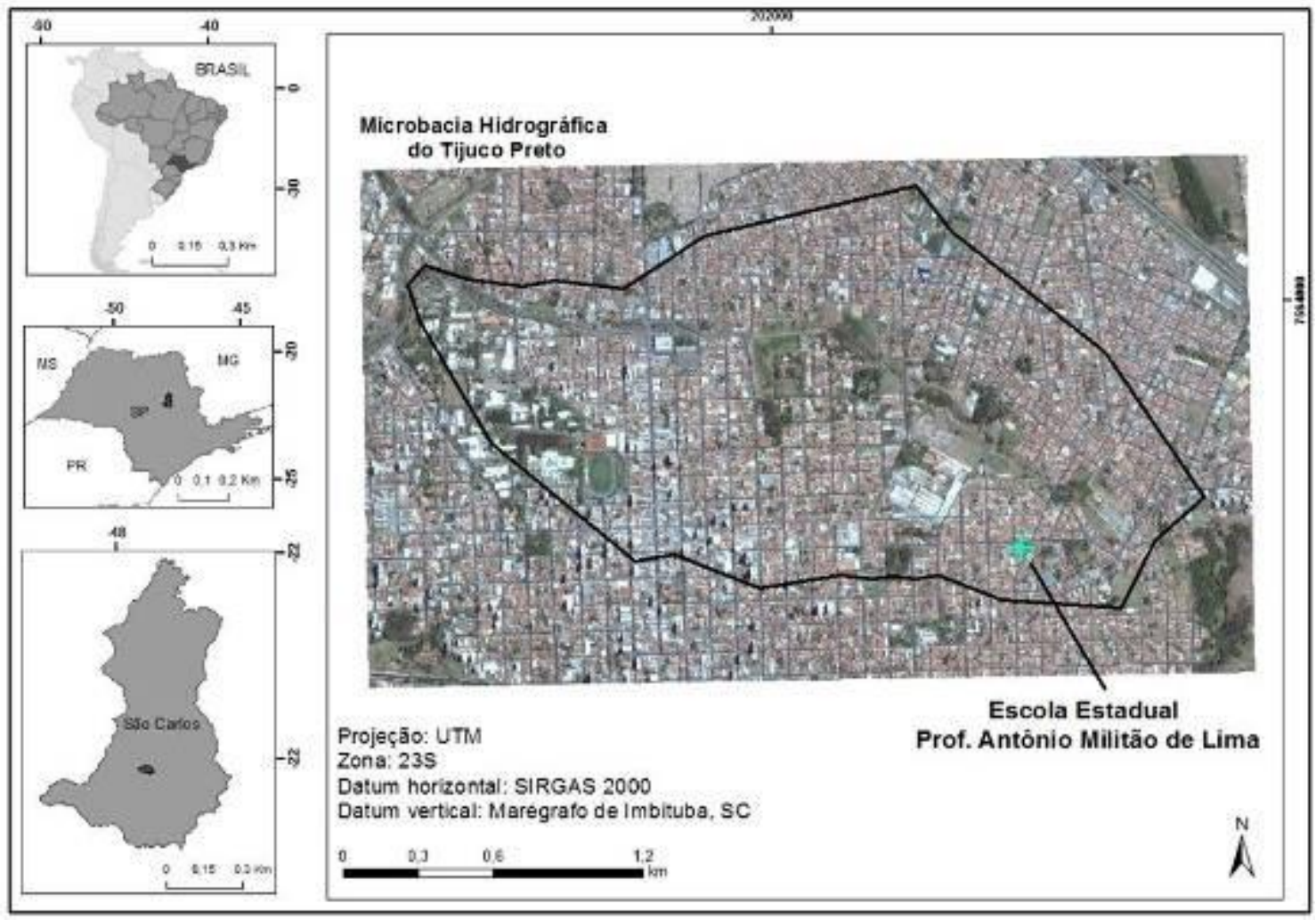

Figura 2: Localização da Escola Estadual Prof. Antônio Militão de Lima na Microbacia Hidrográfica do Tijuco Preto. Fonte: Elaborado pelos autores.

\section{Procedimentos metodológicos}

Para o desenvolvimento do projeto, foram realizadas atividades práticas e interativas com os participantes do Programa Escola da Família ${ }^{7}$ na Escola Estadual Prof. Antônio Militão de Lima. As propostas de atividades foram elaboradas com o intuito de identificar a percepção ambiental dos participantes sobre o problema relatado na área. As ações envolveram uma visita in loco, orientada por uma trilha adjacente ao córrego, iniciada próxima a nascente e finalizada no Parque Linear da área e atividades interativas na escola, após a realização da trilha.

Durante a visita foi distribuído um roteiro, por duplas, contendo o mapa da microbacia com a localização da escola e dos pontos que seriam visitados. Em cada ponto os participantes ressaltaram o que mais os chamou a atenção entre os elementos presentes.

${ }^{7}$ O Programa Escola da Família é desenvolvido pelo Governo do Estado de São Paulo e tem como proposta tornar acessível o espaço escolar público aos jovens e seus familiares durante os finais de semana, sendo que, as atividades devem promover o desenvolvimento de uma cultura participativa e o fortalecimento dos vínculos da escola com a comunidade (SÃO PAULO, 2004). 
Buscando a sensibilização dos participantes sobre a temática resíduos e meio ambiente e a construção de conhecimento sobre o tema, foi desenvolvida, durante a trilha, uma roda de conversa sobre a importância da integridade dos corpos d'água e sobre o descarte adequado de resíduos, de forma a aflorar expectativas positivas de que eles podem melhorar a situação local.

A identificação da percepção dos participantes quanto à problemática, foi conduzida baseada na metodologia da Agenda 21 do Pedaço (ECOAR, 1997), onde foram elaborados o Muro dos Problemas e posteriormente o Rio dos desejos, adaptação da Árvore dos Sonhos. Nestas atividades, realizadas após a trilha, os participantes apontaram quais são os problemas (aspectos negativos) e desejos para a área do córrego frente à situação encontrada durante a realização a visita in loco.

\section{Resultados das atividades desenvolvidas}

O cronograma inicial do projeto previa a realização das atividades em dois encontros (sábado e domingo), dias em que ocorrem as atividades do Programa Escola da Família. Porém, pelo primeiro encontro não ter tido o sucesso esperado, devido à ausência de participantes, o grupo readequou as atividades para um único encontro (sábado). O motivo da readequação foi o receio, por parte dos organizadores, de que o número de participantes reduzisse no segundo encontro, comprometendo o desenvolvimento do projeto.

A execução das atividades ocorreu no dia 22 de novembro de 2014 na Escola Estadual Prof. Antônio Militão de Lima, durante o período matutino. A apresentação dos membros realizadores do projeto, seguida de uma breve explicação sobre os objetivos e justificativa do mesmo deu início as atividades. Em seguida os participantes foram encaminhados até o trecho da trilha e o diálogo com os participantes durante o trajeto demonstrou que a maioria tinha ciência da existência do córrego próximo a eles.

Durante a trilha ocorreram duas paradas, próximo à nascente (Ponto 1) e no Parque Linear do Tijuco Preto (Ponto 2) onde os participantes fizeram anotações seguindo o roteiro entregue aos mesmos. As Figuras 3 e 4 ilustram as paradas nos Pontos 1 e 2 , respectivamente. 


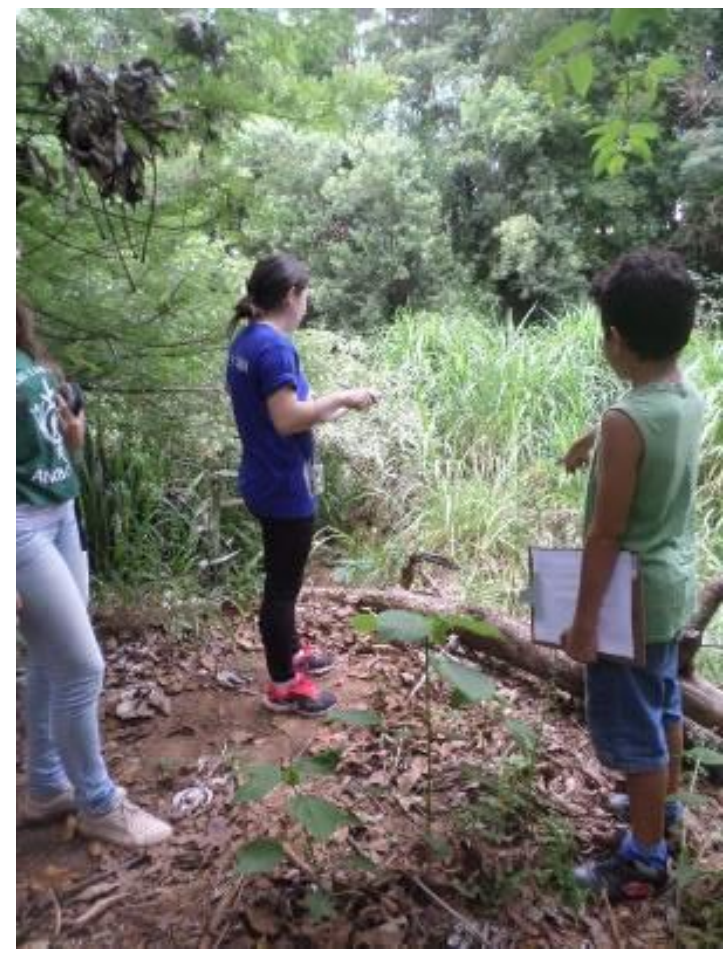

Figura 3: Participantes observando o córrego no ponto 1.

Fonte: Acervo pessoal dos autores.

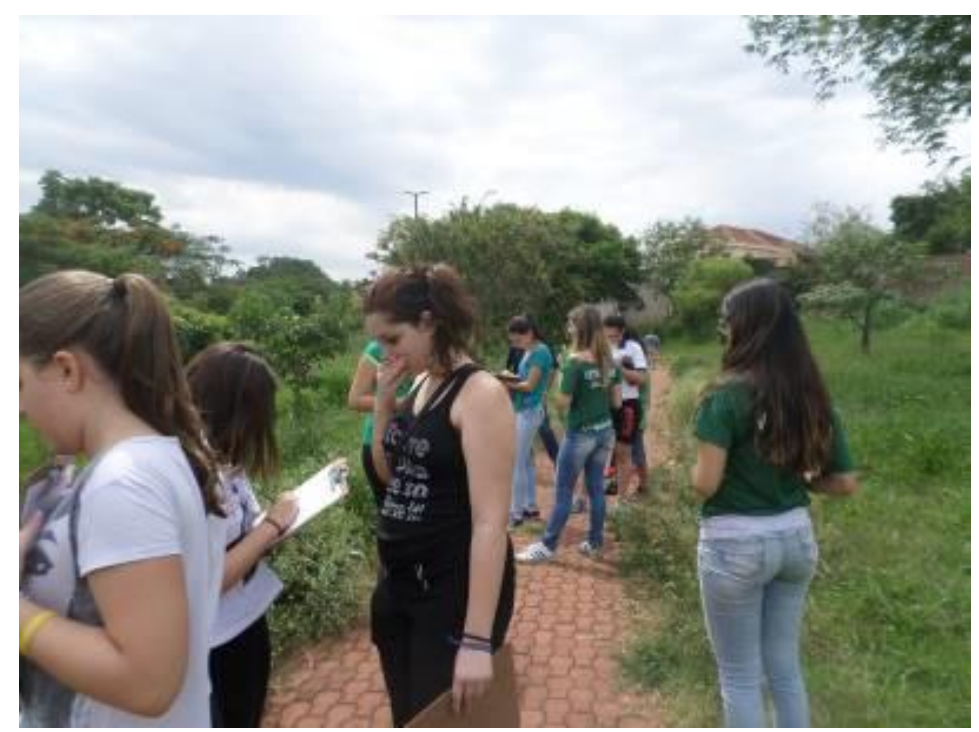

Figura 4. Participantes aplicando o roteiro no ponto 2. Fonte: Acervo pessoal dos autores.

No trajeto de retorno à escola os participantes iniciaram espontaneamente um diálogo sobre "rios poluídos", o que demonstrou o interesse dos mesmos sobre o assunto tratado. O Quadro 1 apresenta as percepções dos participantes nos dois pontos. 
Quadro 1: Percepção dos participantes nos Pontos 1 e 2. Fonte: Autoria Própria.

\begin{tabular}{|c|c|c|c|}
\hline $\operatorname{Sex0}^{8}$ & Idade & Ponto 1 & Ponto 2 \\
\hline Masculino & 11 anos & Tem muita pouca água no rio. & $\begin{array}{l}\text { Tem muito mato no rio e não dá } \\
\text { para ver muito. }\end{array}$ \\
\hline Feminino & 14 anos & $\begin{array}{l}\text { O que chamou minha atenção } \\
\text { foi que não há muita água e há } \\
\text { poluição. }\end{array}$ & $\begin{array}{l}\text { Notei novamente uma poluição } \\
\text { (sofá, pacote de salgadinho), } \\
\text { também tem muito mato, não } \\
\text { dá para ver o rio. }\end{array}$ \\
\hline Feminino & 21 anos & $\begin{array}{l}\text { O que mais chamou minha } \\
\text { atenção foi a pouca } \\
\text { quantidade de água, pois a } \\
\text { muito tempo não chove e a } \\
\text { quantidade de lixo na mata em } \\
\text { volta do rio. }\end{array}$ & $\begin{array}{l}\text { Muita poluição, lugar } \\
\text { abandonado, as pessoas jogam } \\
\text { coisas no rio, como sofá e etc. }\end{array}$ \\
\hline Feminino & 25 anos & $\begin{array}{l}\text { Muita poluição, pouca água, } \\
\text { lugar propício para uso de } \\
\text { drogas e afins. }\end{array}$ & $\begin{array}{l}\text { Falta iluminação e segurança. } \\
\text { No meio de tanto mato e lixo } \\
\text { eis que surge um fio de água. } \\
\text { ponto ser destinado também } \\
\text { para atividade física, } \\
\text { preservação da nascente, falta } \\
\text { manutenção. }\end{array}$ \\
\hline Feminino & 13 anos & $\begin{array}{l}\text { Muito lixo, mato alto e muito } \\
\text { galho quebrado. Mochila na } \\
\text { árvore. }\end{array}$ & $\begin{array}{l}\text { Um sofá no rio, vegetação alta } \\
\text { e flores. Ponte quebrada. }\end{array}$ \\
\hline Feminino & 13 anos & $\begin{array}{l}\text { A quantidade de lixo e a pouca } \\
\text { quantidade de água no } \\
\text { córrego. }\end{array}$ & $\begin{array}{l}\text { Um sofá no rio e muito mato } \\
\text { onde deveria haver o rio. Onde } \\
\text { deveria haver um lugar para } \\
\text { caminhada há muito mato. }\end{array}$ \\
\hline Feminino & 13 anos & $\begin{array}{l}\text { Muito lixo, muito mato e o rio } \\
\text { seco. Coisas penduradas nas } \\
\text { árvores, garrafas, caixas de } \\
\text { leite no chão, muitas sacolas } \\
\text { no chão. }\end{array}$ & $\begin{array}{l}\text { Um sofá jogado no chão, muito } \\
\text { mato, flores lindas e uma ponte } \\
\text { quebrada, várias borboletas, } \\
\text { um parquinho. }\end{array}$ \\
\hline
\end{tabular}

Nota-se pelas informações do Quadro 1 que foram poucos os comentários acerca de aspectos positivos observados nos dois locais, os aspectos negativos predominaram.

Ao retornar para a escola deu-se sequência às atividades com a dinâmica "Muro dos Problemas". Nesta atividade os participantes reuniram-se ao redor do muro para escrever e desenhar nos tijolos, com muita criatividade, os problemas identificados nos pontos visitados. Alguns manifestaram o desejo de expressar não apenas os lados negativos, mas também os aspectos positivos encontrados nos pontos (Figura 5).

8 Para preservar a identidade dos participantes, os mesmos não tiveram seus nomes divulgados neste projeto. Optamos por revelar apenas gênero e idade.

Revbea, São Paulo, V. 11, № 4: 29-41, 2016.

revista brasileira educação ambiental 


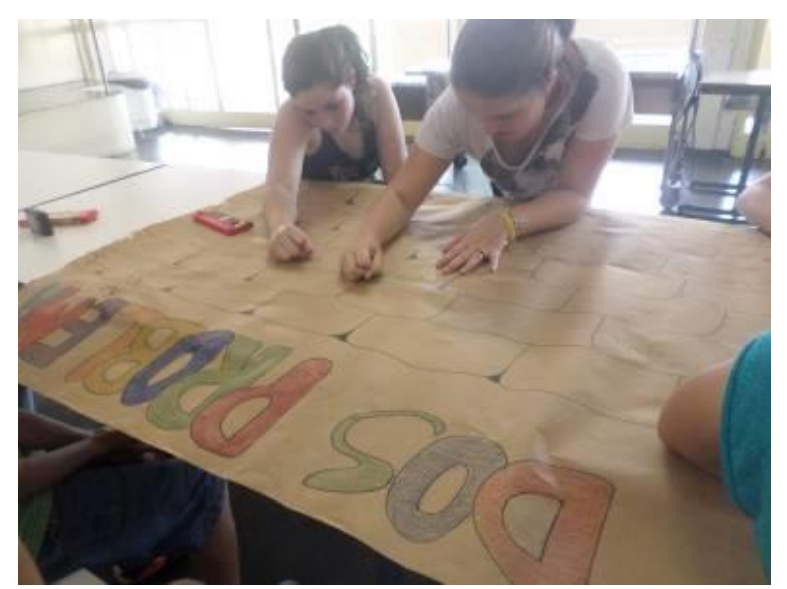

Figura 5: Participantes desenhando no "Muro dos Problemas". Fonte: Acervo Pessoal dos autores.

Após finalizada a atividade do "Muro dos Problemas", deu-se sequência ao "Rio dos Desejos" (Figura 6), onde os participantes escreveram e desenharam suas expectativas em relação ao córrego, ou seja, o que gostariam de apreciar na área. O Quadro 2, expõem as expectativas dos participantes, relatadas no "Rios dos Desejos".

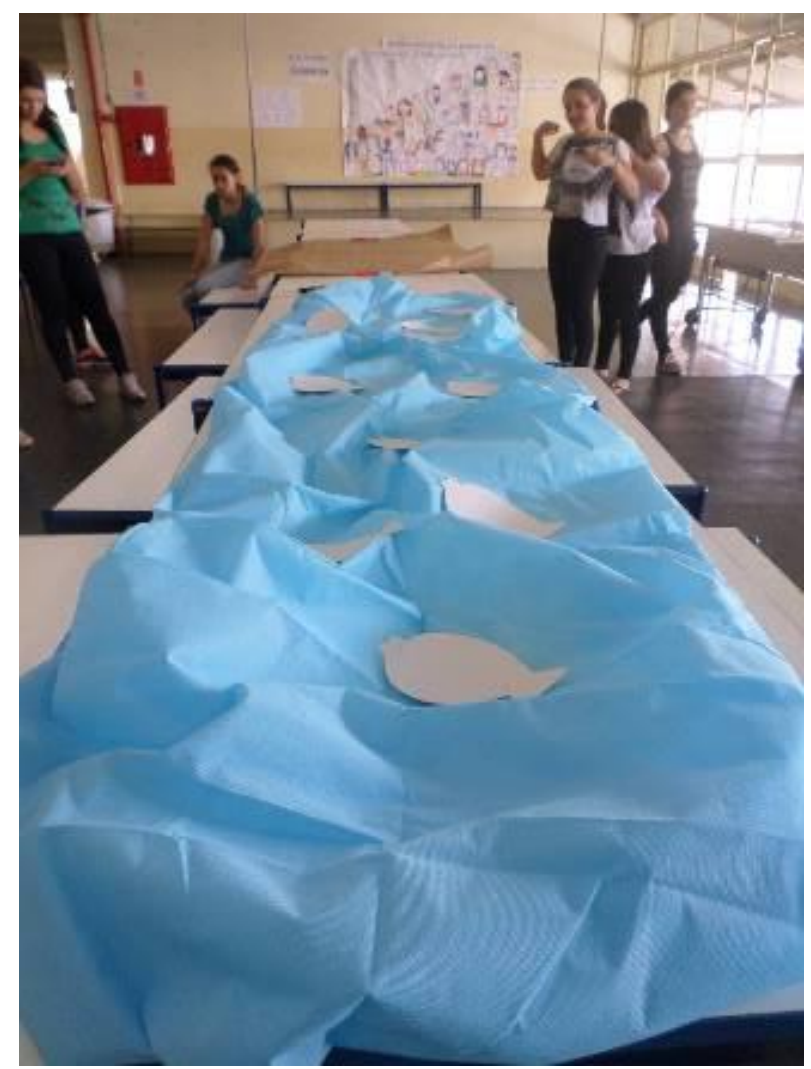

Figura 6: Atividade "Rio dos Desejos".

Fonte: Acervo pessoal dos autores.

Revbea, São Paulo, V. 11, № 4: 29-41, 2016. 
Quadro 2: Desejos expressos no "Rio dos Desejos".

\section{Expectativas dos participantes no "Rio dos Desejos"}

Queria que houvesse muita água e não houvesse poluição

Eu desejo que chova mais na nossa cidade

Que houvesse mais segurança para frequentar

Mais acesso ao rio!

Que fosse possível nadar nele

Que houvesse peixes

Que houvesse menos lixo

Animais e pássaros vivendo livres

Que houvesse mais plantas e menos mato e que houvessem peixes

Que todos pudessem nadar

Passeios com a escola para conscientizar as crianças

Gostaria de ver o rio, poder pescar no rio!

Poderia estar sem poluição!

O rio poderia ter acesso, sem mato nele!

Que ele fosse preservado pela população

Que o rio estivesse cheio

Que a prefeitura sempre corte a vegetação (mato)

Que tivesse peixinhos e que pudesse nadar lá

Que não houvesse sacolas jogadas

Fonte: Autoria Própria.

O encontro foi finalizado com uma roda de conversa com os participantes sobre os desejos que foram expressos na dinâmica do rio, e sobre quais caminhos eles poderiam trilhar para alcançar essa realidade. Outro ponto levantado na discussão foi acerca das responsabilidades para a realização de ações, com o foco em efetivar os desejos descritos. Após um debate, chegou-se à conclusão, juntamente com participantes, da necessidade de uma ação conjunta da Prefeitura Municipal e da população do entorno do córrego para a concretização das expectativas. Por parte da prefeitura deve haver manutenção das áreas e por parte da população o não lançamento de resíduos na área do córrego. 


\section{Avaliação do projeto}

Buscando avaliar a eficácia e eficiência do projeto, aplicou-se três indicadores adaptados de Anadón (2001), que visaram avaliar os pontos de vista e experiências de todos os envolvidos no projeto. Aos indicadores apresentados na sequência atribuiu-se parâmetros de avaliação, Alto, Médio e Baixo, em que Alto correspondeu ao cumprimento total do objetivo em análise, Médio ao cumprimento parcial e Baixo ao não cumprimento.

- Indicador de eficácia: este indicador buscou avaliar quais objetivos foram alcançados e se a realidade alcançada atendeu as previsões.

- Indicador de eficiência: este indicador buscou ponderar as dificuldades (técnicas, de recursos humanos e financeiros) encontradas para a execução do projeto.

- Indicador de impacto: este indicador buscou avaliar quais foram os impactos e as consequências resultantes do desenvolvimento do projeto.

Ao indicador de eficácia atribuiu-se o parâmetro alto, pois, apesar de poucos participantes terem participado das atividades, os objetivos foram alcançados e a realidade atendeu as previsões.

Ao indicador de eficiência o parâmetro médio foi estabelecido, uma vez que a principal dificuldade encontrada foi em relação aos recursos humanos. Os participantes, mesmo tendo apresentado interesse no projeto, não compareceram ao primeiro encontro marcado, principalmente devido ao fato deste se dar em um sábado. Diante do não comparecimento de participantes no primeiro momento os pesquisadores buscaram junto a coordenação da escola alternativas viáveis para o desenvolvimento do projeto, como a proposta de realizar as práticas durante o período de aula, porém não se obteve o apoio necessário. Desta forma, a divulgação do projeto foi intensificada (Figura 7) e, por fim, o projeto foi realizado em um segundo momento contando com sete participantes.

Aplicando o índice de indicador de impacto, foi atribuído a este o parâmetro médio, pois, apesar da sensibilização dos partícipes a respeito da problemática, um maior número de participantes promoveria a maior disseminação de conhecimentos e experiências. 


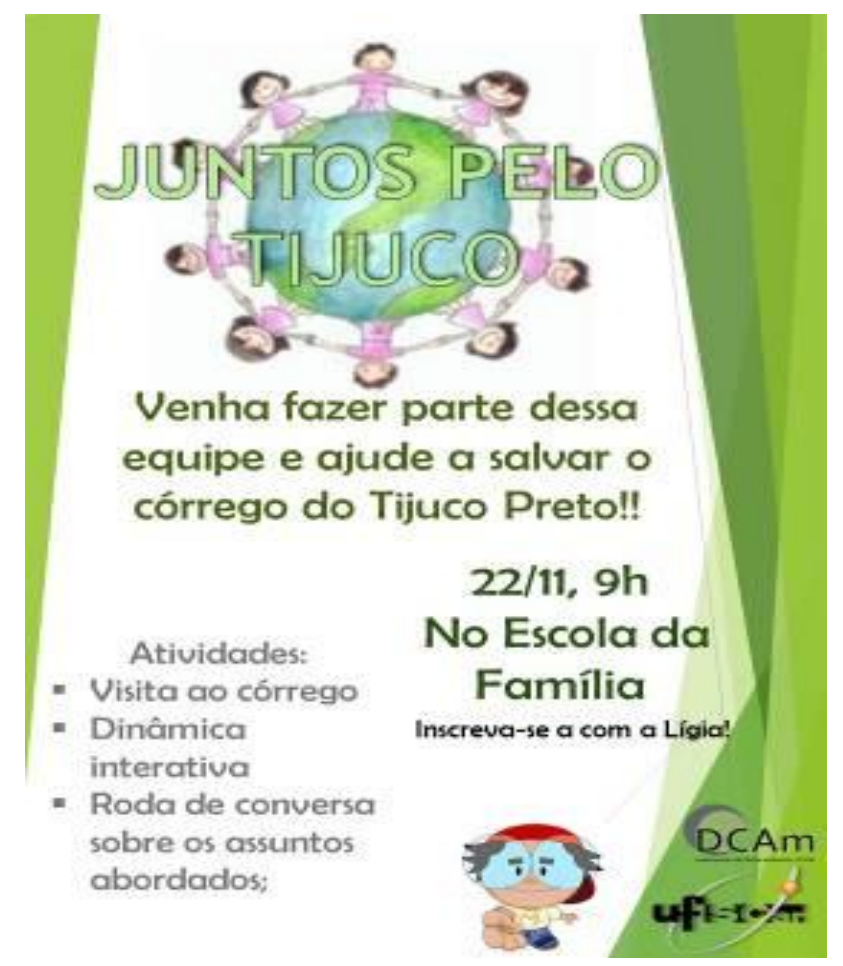

Figura 7. Cartaz de divulgação do projeto.

Fonte: Autoria Própria.

\section{Considerações Finais}

Os resultados obtidos e as análises realizadas evidenciam que um projeto de educação ambiental deve ser flexível e adaptável a cada realidade. Apesar das dificuldades encontradas para o desenvolvimento do projeto os objetivos foram atingidos, porém, um maior número de participantes enriqueceria os resultados e a sensibilização da população do entorno do córrego do Tijuco Preto se difundiria.

Projetos deste gênero são de significativa importância para a formação de cidadãos com consciência ambiental. Para que seus resultados sejam efetivos deve haver interesse, parceria e apoio de forma concreta entre a coordenação da escola e a organização do projeto.

Outro ponto a ser destacado para o desenvolvimento e sucesso de projetos de EA é o apoio por legislações municipais. Assim, é importante assinalar que o projeto apresentado neste artigo apresenta relações com a legislação municipal de educação ambiental - Política Municipal de Educação Ambiental de São Carlos (Lei $n^{\circ} 14.795$ ), que define, no Artigo 1ํㅡ, o objetivo da política como:

Promover a formação na área de educação ambiental abrangendo as escolas, os espaços não formais e públicos de diferentes seguimentos da sociedade (SÃO CARLOS, 2008a). 
O município de São Carlos conta também com um Programa Municipal de Educação Ambiental de São Carlos- ProMEA- SC, no qual o projeto aproxima-se de três linhas de ação, vê-se:

Promover estudos sobre percepção ambiental e representações de meio ambiente dos grupos envolvidos que subsidiem as trocas de saberes e as formulações de ações subsequentes (4ํㅡㄴ Linha de Ação do ProMEA-SC).

Promover a Educação Ambiental comunitária (nas associações de bairro, centros comunitários, etc.) (25 Linha de Ação do ProMEA-SC)

Promover e estimular a interação entre ações culturais envolvendo formas de expressão artística como música, teatro, cinema, dança e temática ambiental em espaços escolares, praças, centros comunitários, etc. (31ํㅡㄴ Linha de Ação) (SÃO CARLOS, 2008b).

Neste panorama, a proximidade das ações desenvolvidas no projeto com regulações municipais reforça o potencial de práticas de EA na promoção de cidadãos conscientes e empenhados em preservar e cuidar do meio ambiente que os circunda.

\section{Referências}

ANADÓN, M. Quando avaliar é formar. In: Santos, J.E.; Sato, M. A contribuição da Educação Ambiental à esperança de Pandora. 604 p. 2001.

BRASIL. CARTA DA TERRA. O texto da Carta da Terra - Brasil, 2000. Disponível em <http://www.cartadaterrabrasil.org/prt/text.html>. Acesso em 28 de setembro de 2014.

CARVALHO, L.M. Educação e Meio Ambiente na Escola Fundamental. Projeto Revista de Educação, Porto Alegre, v. 2, p. 9-18, 1999.

JACOBI, P.R. Educação Ambiental: o desafio da construção de um pensamento crítico, complexo e reflexivo. Educação e Pesquisa, São Paulo, v. 31, n. 2, p. 233-250, maio/ago. 2005.

INSTITUTO ECOAR PARA CIDADANIA, Desafio das Águas- Agenda 21 do Pedaço. Anais do Fórum de Educação Ambiental /Encontro da Rede Brasileira de Educação Ambiental. 1997.

SANTI, A.D.; MAZZUCO, G.G. Resíduos sólidos urbanos: Diagnóstico do processo de disposição na microbacia do Tijuco Preto. UFSCar: São Carlos, 2014. 
SÃO CARLOS. Lei $n^{\circ}$ 14.795, de 28 de novembro de 2008. Institui a Política Municipal de Educação Ambiental e dá outras providências. São Carlos, 2008a.

SÃO CARLOS. Resolução COMDEMA-SC n 1, de 25 de novembro de 2008. Programa Municipal de Educação Ambiental de São Carlos. 2008b.

SÃO PAULO. Decreto $\mathbf{n}^{\circ} \mathbf{4 8 . 7 8 1}$, de 7 de Julho de 2004. Institui o Programa Escola da Família. Disponível em: $<$ http://escoladafamilia.fde.sp.gov.br/v2/Arquivos/Regulamento/Decreto\%20n\% C2\%BA\%2048.781\%20-

\%20Programa\%20Escola\%20da\%20Fam\%C3\%ADlia.pdf> Acesso em 5 de outubro de 2014.

SAUVÉ, L. Educação Ambiental: possibilidades e limitações. Educação e Pesquisa, vol.31, n.2, São Paulo, 2005. 